\title{
Change in the perioperative blood glucose and blood lactate levels of non-diabetic patients undergoing coronary bypass surgery
}

\author{
CHUNJIAN SHEN $^{1,3}$, TIANXIANG GU ${ }^{1}$, LILI GU ${ }^{2}$, ZHONGYI XIU $^{1}$, ZHIWEI ZHANG $^{1}$, \\ ENYI SHI ${ }^{1}$, YUHAI ZHANG ${ }^{1}$ and $\mathrm{CHUN}_{\mathrm{WANG}}{ }^{1}$ \\ ${ }^{1}$ Department of Cardiac Surgery, The First Hospital of China Medical University, Shenyang, Liaoning 110001; \\ ${ }^{2}$ China Medical University, Shenyang, Liaoning 110001; ${ }^{3}$ Shenzhou Hospital of Shenyang Medical College, \\ Shenyang, Liaoning 110002, P.R. China
}

Received April 16, 2013; Accepted July 29, 2013

DOI: $10.3892 / \mathrm{etm} .2013 .1268$

\begin{abstract}
In the present study, a retrospective analysis of the trends and factors affecting blood glucose and blood lactate levels was carried out for non-diabetic adult patients who had undergone coronary artery bypass graft (CABG) surgery. Between October 2009 and October 2011, 200 non-diabetic adult patients undergoing CABG surgery were examined. Glucose and lactic acid levels were observed successively during surgery [following the induction of anesthesia, cardiopulmonary bypass (CPB), aortic cross-clamping and aortic stop flow infusion], at the end of surgery and after surgery $[1,6,12,24$ and $48 \mathrm{~h}$ after admission to the intensive care unit (ICU)]. The results of blood gas analyses and other related indicators for trend analysis were investigated. The peak blood glucose and blood lactate levels during CPB, as well as other CPB factors, were also analyzed. Following aortic cross-clamping, intraoperative blood glucose and blood lactate levels increased gradually with increasing operative time. Postoperatively, blood glucose and blood lactate levels continued to rise. Blood glucose and blood lactic acid levels during CPB were positively correlated. The blood glucose and blood lactate levels of non-diabetic adult patients undergoing CABG increased gradually with operative time following aortic cross-clamping. Moreover, blood glucose and blood lactate levels were positively correlated with the duration of $\mathrm{CPB}$ and duration of aortic cross-clamping.
\end{abstract}

\section{Introduction}

During extracorporeal circulation in cardiac surgery, also known as cardiopulmonary bypass (CPB), the internal envi-

Correspondence to: Professor Tian-Xiang Gu, Department of Cardiac Surgery, The First Hospital of China Medical University, 155 Nanjing Street, Heping, Shenyang, Liaoning 110001, P.R. China E-mail: gutianxiangcn@126.com

Key words: coronary artery bypass graft, cardiopulmonary bypass, blood glucose, blood lactate ronment undergoes significant changes due to anesthesia, $\mathrm{CPB}$, surgical operation and other factors. The phenomenon of increased blood glucose and blood lactate levels during the perioperative period is often observed, even in patients with hyperglycemia (1-5) 60-70\% (4) and lactic acidosis (6-8) $10-20 \%(9,10)$. This increases the incidence of postoperative complications and mortality $(1,8,9,11)$. At present, patients with diabetes, particularly those who have previously undergone $\mathrm{CPB}$ or coronary artery bypass graft (CABG) surgery of the downstream arteries, more frequently experience and report blood glucose level changes. Treatment strategies have been developed for these patients. Reports of changes in blood glucose and lactate levels and the need for intervention in non-diabetic patients are rare (4). In the present investigation, a dynamic study of the trends of blood glucose and lactate levels in non-diabetic adult patients undergoing CABG surgery was carried out.

This study was conducted in order to explore the prevention and treatment of high levels of blood glucose and lactic acidosis, in an attempt to improve CPB management, maintain the internal environment during surgery, reduce the incidence of CPB-related complications and improve prognosis.

During cardiac surgery, a continued increase of perioperative blood glucose levels to $>200 \mathrm{mg} / \mathrm{dl}$ is considered to be hyperglycemia (12-16). High blood glucose increases the risk of postoperative mortality (1-5), postoperative infections $(3,17)$, myocardial injury (18-20), stroke $(2,21)$ and neurological dysfunction (2,22). A number of perioperative glycemic control standards have been established; however, reports concerning their clinical effectiveness are inconsistent $(23,24)$. Ruesch et al (16) suggested that intraoperative blood glucose levels of $>200 \mathrm{mg} / \mathrm{dl}$ require treatment (16). Lazar et al (14) reported that the perioperative management of blood glucose significantly improved prognosis in diabetic patients $(n=141)$ with blood glucose levels of 125-200 mg/dl who underwent cardiac surgery. Based on 1,548 cases, Van den Berghe et al $(25,26)$ suggested that blood glucose levels that reach $80-110 \mathrm{mg} / \mathrm{dl}$ after surgery should be controlled. Carr et al (27) reported that the perioperative blood glucose levels of patients undergoing cardiac surgery should be reduced to $110 \mathrm{mg} / \mathrm{dl}$. Lazar (28) and Quinn et al (29) also emphasized the importance of postoperative management of blood glucose levels in non-diabetic and 
diabetic patients who undergo cardiac surgery. A blood lactate concentration of $>3.0 \mathrm{mmol} / \mathrm{l}$ during the perioperative period of cardiac surgery is considered to be lactic acidosis $(7,8)$. Whether lactic acidosis during CPB increases postoperative mortality remains controversial. Demers et al (9) reported that a peak blood lactate level of $\geq 4.0 \mathrm{mmol} / 1$ correlates with postoperative complications and mortality, based on a study of 1,376 cases. However, Ranucci et al (6) reported that lactic acidosis only increases the incidence of postoperative complications. Maillet et al (8) showed that blood lactate concentrations $>3.0 \mathrm{mmol} / \mathrm{l}$ correlates with poor prognosis and an increased death rate following intensive care unit (ICU) admission.

In the present study, 200 non-diabetic patients undergoing CABG surgery were analyzed in order to explore treatment strategies for high blood glucose levels and lactic acidosis, and thus improve CPB management and prognosis.

\section{Materials and methods}

Patients. A total of 200 non-diabetic adult patients undergoing CABG surgery in Shenzhou Hospital (Shenyang, China) between October 2009 and October 2011 were included in this study. This study was conducted in accordance with the Declaration of Helsinki and with approval from the Ethics Committee of Shenzhou Hospital (Shenyang, China). Written informed consent was obtained from all participants.

Inclusion criteria were as follows: i) non-diabetic patients undergoing CABG surgery; ii) 31-65 years old (mean, $51 \pm 9$ years old); iii) cardiac function, class II-III [New York Heart Association (NYHA) functional classification]; and iv) an ejection fraction $(\mathrm{EF})>35 \%$.

Exclusion criteria were as follows: i) diabetic patients, individuals exhibiting preoperative symptoms of diabetes and with random blood glucose levels $\geq 11.1 \mathrm{mmol} / \mathrm{l}(200 \mathrm{mg} / \mathrm{dl})$ or fasting blood glucose levels $\geq 7.0 \mathrm{mmol} / 1$ (126 mg/dl); ii) liver or kidney dysfunction, abnormal liver function (alanine aminotransferase $>40 \mathrm{U} / \mathrm{l}$ ) or renal insufficiency [blood urea nitrogen $(\mathrm{BUN})>16.0 \mathrm{mmol} / \mathrm{l}$ or creatinine $(\mathrm{Cr})>170 \mu \mathrm{mol} / \mathrm{l}]$; iii) second surgery; iv) acute myocardial infarction and acute endocarditis; and v) cachexia with an intra-aortic balloon pump (counterpulsation) or left ventricular assist device.

Data extraction. Blood glucose and blood lactate levels were obtained successively during surgery [after the induction of anesthesia, CPB, aortic cross-clamping (5-10 min) and aortic stop flow infusion (10 min after CPB, lasting for $10 \mathrm{~min}$ )], at the end of surgery and after surgery $(1,6,12,24$ and $48 \mathrm{~h}$ following admission to the ICU). Results of blood gas analyses and other related indicators were recorded for trend analysis.

Statistical analysis. All data were statistically analyzed using SPSS 11.5 (SPSS, Inc., Chicago, IL, USA). Measured data were expressed as the mean \pm SD and compared using Student's t-test and Spearman's correlation analysis. $\mathrm{P}<0.05$ was considered to indicate a statistically significant difference.

\section{Results}

Changes in perioperative blood glucose levels. During surgery, after aortic cross-clamping, blood glucose levels increased gradually with increasing operative time. The arterial (aorta) blood glucose levels significantly increased after the start of the operation and blood glucose levels peaked at the end of surgery.

After surgery, blood glucose levels continued to rise, and $6 \mathrm{~h}$ following admission to the ICU, they reached a peak of $15.01 \pm 4.91 \mathrm{mmol} / \mathrm{l}$. After $12 \mathrm{~h}$, the blood glucose levels began to decline and after $24 \mathrm{~h}$, they returned to near-normal levels. However, a further decline (to $8.05 \pm 2.32 \mathrm{mmol} / \mathrm{l}$ ) was observed after $48 \mathrm{~h}$ (Tables I and II; Fig. 1).

Changes in perioperative blood lactate levels. During surgery, after aortic cross-clamping, blood lactate levels increased gradually with increasing surgery time. The mean arterial (aorta) blood lactate level was $>4.88 \mathrm{mmol} / \mathrm{l}$ and lactic acidosis was observed. Following aortic stop flow infusion and CPB, blood lactic acid levels continued to rise significantly in a linear manner. The peak intraoperative blood lactate level occurred at the end of surgery.

After surgery, blood lactate levels continued to rise, and $6 \mathrm{~h}$ following admission to the ICU, they reached a peak of $7.66 \pm 2.33 \mathrm{mmol} / \mathrm{l}$. Thereafter, the blood lactate levels began to decline and returned to normal levels after $24 \mathrm{~h}$. After $48 \mathrm{~h}$, the blood lactate level was $<2.0 \mathrm{mmol} / \mathrm{l}$ (Tables I and II; Fig. 2).

Correlation analysis. As shown in Tables III and IV, the peak blood glucose and blood lactate levels during CPB were positively correlated $(\mathrm{r}=0.312, \mathrm{P}=0.009)$. Peak blood glucose levels were positively correlated with the duration of the $\mathrm{CPB}$ procedure and aortic cross-clamping $(\mathrm{r}=0.386, \mathrm{P}=0.001$ and $\mathrm{r}=0.412, \mathrm{P}<0.001$, respectively). Peak blood lactate levels were also positively correlated with the duration of the CPB procedure and duration of aortic cross-clamping $(\mathrm{r}=0.489, \mathrm{P}<0.001$ and $\mathrm{r}=0.467, \mathrm{P}<0.001$, respectively).

Blood lactate levels increased with increasing blood glucose levels. During CPB, blood glucose and blood lactate levels exhibited increasing trends that correlated with the duration of $\mathrm{CPB}$ and aortic cross-clamping.

\section{Discussion}

Lazar et al (14) observed that the intraoperative blood glucose levels of diabetic patients undergoing cardiac surgery increase gradually with increasing operative time when blood glucose levels are not controlled, and 6-12 $\mathrm{h}$ after CPB these levels reach a peak of $>250 \mathrm{mg} / \mathrm{dl}(13.9 \mathrm{mmol} / \mathrm{l})$. Therefore, during the perioperative period, insulin should be used to maintain blood glucose levels at $<200 \mathrm{mg} / \mathrm{dl}(11.1 \mathrm{mmol} / \mathrm{l})$. Prasad et al (4) reported that $70 \%$ of non-diabetic patients are often observed to have blood glucose levels $>200 \mathrm{mg} / \mathrm{dl}$ (11.1 mmol/l) during CPB and $61 \%$ are considered to have high blood glucose. Of those who acquire postoperative hyperglycemia, 22\% continue to have the condition. During cardiac surgery, perioperative blood glucose levels $>200 \mathrm{mg} / \mathrm{dl}(11.1 \mathrm{mmol} / \mathrm{l})$ are considered to be hyperglycemic. The incidence of intraoperative hyperglycemia is comparable to that of postoperative infection $(3,17)$, myocardial injury (18-20), postoperative neurological injury, cognitive dysfunction and other complications $(2,22)$ that result in adverse prognosis.

In the present study, intraoperative blood glucose levels determined during aortic cross-clamping at the aorta gradu- 
Table I. Intraoperative blood glucose and blood lactate level changes (mean \pm SD).

\begin{tabular}{|c|c|c|c|c|c|}
\hline Variable & $\begin{array}{l}\text { After induction of } \\
\text { anesthesia }\end{array}$ & $\begin{array}{l}\text { After clamping } \\
\text { the aorta }\end{array}$ & $\begin{array}{l}\text { After opening } \\
\text { the aorta }\end{array}$ & Stop CPB & End of surgery \\
\hline Blood glucose (mmol/l) & $5.49 \pm 0.98$ & $6.71 \pm 1.58$ & $9.92 \pm 3.03$ & $11.43 \pm 2.87$ & $11.83 \pm 4.32$ \\
\hline Blood lactate (mmol/1) & $0.89 \pm 0.32$ & $1.78 \pm 0.71$ & $4.88 \pm 1.01$ & $6.24 \pm 2.90$ & $6.78 \pm 3.12$ \\
\hline
\end{tabular}

$\mathrm{CPB}$, cardiopulmonary bypass.

Table II. Postoperative blood glucose and blood lactate level changes (mean \pm SD).

Time in the ICU (h)

\begin{tabular}{lrrrrr}
\cline { 2 - 5 } Variable & \multicolumn{1}{c}{1} & \multicolumn{1}{c}{6} & \multicolumn{1}{c}{12} & 24 & 48 \\
\hline Blood glucose (mmol/l) & $12.34 \pm 3.62$ & $15.01 \pm 4.91$ & $11.33 \pm 3.65$ & $9.81 \pm 2.59$ & $8.05 \pm 2.32$ \\
Blood lactate (mmol/l) & $6.98 \pm 3.78$ & $7.66 \pm 2.33$ & $5.10 \pm 2.13$ & $3.26 \pm 2.00$ & $1.89 \pm 0.96$
\end{tabular}

ICU, intensive care unit.

Table III. Peak glucose univariate analysis during CPB.

\begin{tabular}{lcr}
\hline CPB-related factors & $\begin{array}{c}\text { Correlation } \\
\text { coefficient (r) }\end{array}$ & P-value \\
\hline Lactate peak & 0.312 & 0.009 \\
CPB time & 0.386 & 0.001 \\
Aortic cross-clamping time & 0.412 & $<0.001$ \\
\hline
\end{tabular}

$\mathrm{CPB}$, cardiopulmonary bypass.

Table IV. Peak blood lactate univariate analysis during CPB.

\begin{tabular}{lcr}
\hline CPB-related factors & $\begin{array}{c}\text { Correlation } \\
\text { coefficient (r) }\end{array}$ & P-value \\
\hline Glucose peak & 0.312 & 0.009 \\
CPB time & 0.489 & $<0.001$ \\
Aortic cross-clamping time & 0.467 & $<0.001$ \\
\hline
\end{tabular}

CPB, cardiopulmonary bypass.

ally increased with increasing operative time, reaching levels of $9.92 \pm 3.03 \mathrm{mmol} / 1$. Following aortic stop flow infusion and CPB, blood glucose increased to $>11.1 \mathrm{mmol} / \mathrm{l}$. High blood glucose levels were observed at the end of surgery, and intraoperative blood glucose levels reached a peak of $11.83 \pm 4.32 \mathrm{mmol} / \mathrm{l}$. Correlation analyses revealed that during $\mathrm{CPB}$, peak blood glucose levels and the duration of aortic cross-clamping were positively correlated. These observations indicate that blood glucose levels of non-diabetic adult patients undergoing heart valve surgery gradually increase with increasing operative time and that hyperglycemia occurs

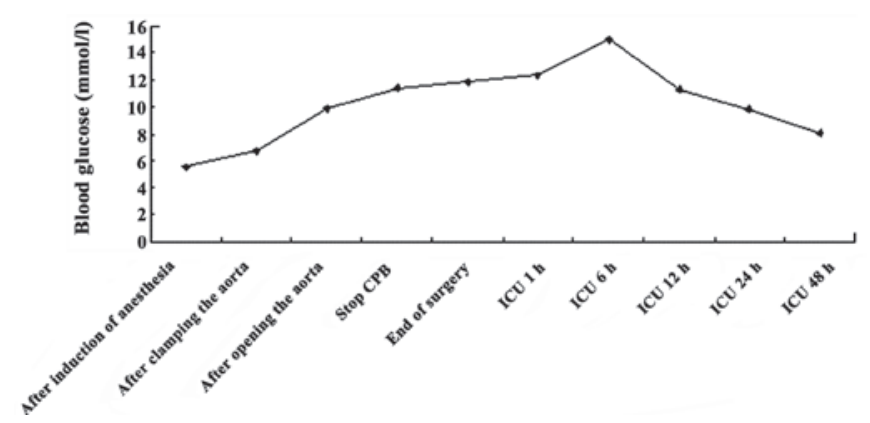

Figure 1. Intraoperative and postoperative trends in blood glucose levels following CABG in 200 adult non-diabetic patients. CABG, coronary artery bypass graft; $\mathrm{CPB}$, cardiopulmonary bypass; ICU, intensive care unit.

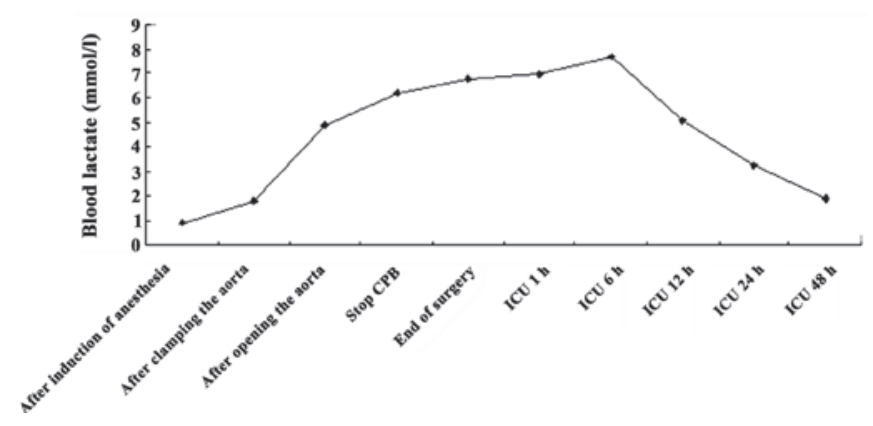

Figure 2. Intraoperative and postoperative trends in blood lactate levels following CABG surgery in 200 adult non-diabetic patients. CABG, coronary artery bypass graft; $\mathrm{CPB}$, cardiopulmonary bypass; ICU, intensive care unit.

during surgery. This suggests that the prevention and treatment of hyperglycemia is required during cardiac surgery.

Following surgery, blood glucose levels continued to rise and reached a peak of $15.01 \pm 4.91 \mathrm{mmol} / \mathrm{l}$ after $6 \mathrm{~h}$ in the ICU. Blood glucose levels decreased significantly to nearly $11.33 \mathrm{mmol} / \mathrm{l}$ after $12 \mathrm{~h}$, returned to near-normal levels at $24 \mathrm{~h}$ 
and decreased to $8.05 \pm 2.32 \mathrm{mmol} / \mathrm{l}$ at $48 \mathrm{~h}$. These observations indicate that an intervention for high blood glucose is necessary.

Lazar et al (14) observed that blood lactic acid levels increase with increasing operative time during $\mathrm{CPB}$, reach peak levels 6-12 $\mathrm{h}$ after $\mathrm{CPB}$ and then decrease. The authors considered the intraoperative control of blood glucose to aid in the regulation of lactic acid levels. Ranucci et al (6) also reported that blood lactate levels significantly rise with the increasing duration of CPB. During heart surgery, a blood lactate concentration $>3.0 \mathrm{mmol} / 1$ is considered to be lactic acidosis. Based on a large clinical study that included 1,376 cases, Demers et al (9) reported that blood lactate levels reach a peak of $\geq 4.0 \mathrm{mmol} / 1$ during $\mathrm{CPB}$ and that these levels correlate with the incidence of postoperative complications and mortality.

In the current study, intraoperative blood lactate levels determined during aortic cross-clamping at the aorta increased gradually with increasing operative time. Furthermore, during surgery, the levels of lactate in blood samples from the aorta reached $4.88 \pm 1.01 \mathrm{mmol} / \mathrm{l}$ and lactic acidosis was observed. Following aortic stop flow infusion and CPB, blood lactic acid levels continued to increase linearly and achieved peak levels at the end of surgery. Correlation analyses revealed that the peak levels of blood lactate were positively correlated with the duration of CPB and aortic cross-clamping. These observations indicate that blood lactate levels in non-diabetic adult patients undergoing heart valve surgery gradually increase with increasing operative time and that lactic acidosis occurs during surgery. During CPB, changes in blood lactate levels are extremely apparent and peak blood lactate levels reach high values, indicating that a number of relevant factors, other than those associated with the operation, significantly impact blood lactate levels during CPB.

Following surgery, blood lactate levels continued to rise and reached a peak of $7.66 \pm 2.33 \mathrm{mmol} / 16 \mathrm{~h}$ following admission to the ICU. The levels exhibited a downward trend towards normal ranges after $24 \mathrm{~h}$, and returned to normal levels $(<2.0 \mathrm{mmol} / \mathrm{l})$ after $48 \mathrm{~h}$. These findings indicate that blood lactate levels are highest 1-6 h following surgery.

Ranucci et al (6) observed that during CPB, high blood lactate levels are often accompanied by elevated blood glucose levels. During CPB, certain factors often lead to insulin resistance, which results in the failure of absorption and utilization of glucose by tissues. This phenomenon causes lactic acid generation through anaerobic metabolism and subsequently, lactic acid accumulation that results in lactic acidosis.

Correlation analyses in the current study revealed that during $\mathrm{CPB}$, the peak blood glucose and blood lactate levels were correlated $(\mathrm{r}=0.312, \mathrm{P}=0.009)$, indicating that blood glucose increases with increasing blood lactate levels. During $\mathrm{CPB}$, the peak blood glucose and blood lactate levels gradually increased with increasing operative time, which was accompanied by the occurrence of hyperglycemia and lactic acidosis.

In the present study, changes in blood glucose and blood lactate levels were observed during CPB. These observations suggest that CPB-related factors significantly alter the internal environment, resulting in elevated blood glucose and blood lactate levels. Therefore, the enhancement of CPB management to improve the internal environment by controlling intraopera- tive blood glucose and blood lactate levels is likely to reduce the incidence of CPB-related complications and improve the prognosis of patients.

\section{References}

1. Doenst T, Wijeysundera D, Karkouti K, et al: Hyperglycemia during cardiopulmonary bypass is an independent risk factor for mortality in patients undergoing cardiac surgery. J Thorac Cardiovasc Surg 130: 1144, 2005.

2. Grocott HP: Glucose and outcome after cardiac surgery: what are the issues? J Extra Corpor Technol 38: 65-67, 2006.

3. Rassias AJ, Givan AL, Marrin CA, Whalen K, Pahl J and Yeager MP: Insulin increases neutrophil count and phagocytic capacity after cardiac surgery. Anesth Analg 94: 1113-1119, 2002.

4. Prasad AA, Kline SM, Schuler HG and Sukernik MR: Clinical and laboratory correlates of excessive and persistent blood glucose elevation during cardiac surgery in nondiabetic patients: a retrospective study. J Cardiothorac Vasc Anesth 21: 843-846, 2007.

5. Krinsley J: Perioperative glucose control. Curr Opin Anaesthesiol 19: 111-116, 2006.

6. Ranucci M, Isgrò $G$, Romitti F, Mele S, Biagioli B and Giomarelli P: Anaerobic metabolism during cardiopulmonary bypass: the predictive value of carbon dioxide derived parameters. Ann Thorac Surg 81: 2189-2195, 2006.

7. Takala J, Uusaro A, Parviainen I and Ruokonen E: Lactate metabolism and regional lactate exchange after cardiac surgery. New Horiz 4: 483-492, 1996.

8. Maillet JM, Le Besnerais P, Cantoni M, et al: Frequency, risk factors, and outcome of hyperlactatemia after cardiac surgery. Chest 123: 1361-1366, 2003.

9. Demers P, Elkouri S, Martineau R, Couturier A and Cartier R Outcome with high blood lactate levels during cardiopulmonary bypass in adult cardiac operation. Ann Thorac Surg 70: 2082-2086, 2000.

10. Ranucci M, De Toffol B, Isgro G, Romitti F, Conti D and Vicentini M: Hyperlactatemia during cardiopulmonary bypass: determinants and impact on postoperative outcome. Crit Care 10: R167, 2006.

11. Rashkin MC, Bosken C and Baughman RP: Oxygen delivery in critically ill patients. Relationship to blood lactate and survival. Chest 87: 580-584, 1985.

12. Anderson RE, Brismar K, Barr G and Ivert T: Effects of cardiopulmonary bypass on glucose homeostasis after coronary artery bypass surgery. Eur J Cardiothorac Surg 28: 425-430, 2005.

13. Lazar HL, Chipkin S, Philippides G, Bao Y and Apstein C: Glucose-insulin-potassium solutions improve outcomes in diabetics who have coronary artery operations. Ann Thorac Surg 70: 145-150, 2000.

14. Lazar HL, Chipkin SR, Fitzgerald CA, Bao Y, Cabral H and Apstein CS: Tight glycemic control in diabetic coronary artery bypass graft patients improves perioperative outcomes and decreases recurrent ischemic events. Circulation 109: 1497-1502, 2004.

15. Furnary AP, Gao G, Grunkemeier GL, et al: Continuous insulin infusion reduces mortality in patients with diabetes undergoing coronary artery bypass grafting. J Thorac Cardiovasc Surg 125: 1007-1021, 2003.

16. Ruesch S and Levy JH: The postcardiopulmonary bypass period: a systems approach. In: A Practical Approach to Cardiac Anesthesia. 3rd edition. Hensley FA, Martin DE and Gravlee GP, (eds). Lippincott Williams \& Wilkins, Philadelphia, pp235-249, 2003.

17. Trick WE, Scheckler WE, Tokars JI, et al: Modifiable risk factors associated with deep sternal site infection after coronary artery bypass grafting. J Thorac Cardiovasc Surg 119: 108-114, 2000.

18. Fonseca VA: Management of diabetes mellitus and insulin resistance in patients with cardiovascular disease. Am J Cardiol 92: 50J-60J, 2003.

19. Albacker TB, Carvalho G, Schricker T and Lachapelle K: Myocardial protection during elective coronary artery bypass grafting using high-dose insulin therapy. Ann Thorac Surg 84: 1920-1927, 2007.

20. Oliver MF and Opie LH: Effect of glucose and fatty acids on myocardial ischaemia and arrhythmias. Lancet 343: 155-158, 1994. 
21. Parsons MW, Barber PA, Desmond PM, et al: Acute hyperglycemia adversely affects stroke outcome: a magnetic resonance imaging and spectroscopy study. Ann Neurol 52: 20-28, 2002.

22. Quinn DW, Pagano D and Bonser RS: Glucose and insulin influences on heart and brain in cardiac surgery. Semin Cardiothorac Vasc Anesth 9: 173-178, 2005.

23. Gearhart MM and Parbhoo SK: Hyperglycemia in the critically ill patient. AACN Clin Issues 17: 50-55, 2006

24. Wade AO and Cordingley JJ: Glycaemic control in critically ill patients with cardiovascular disease. Curr Opin Crit Care 12: 437-443, 2006.

25. van den Berghe G, Wouters P, Weekers F, et al: Intensive insulin therapy in critically ill patients. N Engl J Med 345: 1359-1367, 2001.
26. Van den Berghe G, Wouters PJ, Bouillon R, et al: Outcome benefit of intensive insulin therapy in the critically ill: Insulin dose versus glycemic control. Crit Care Med 31: 359-366, 2003.

27. Carr JM, Sellke FW, Fey M, et al: Implementing tight glucose control after coronary artery bypass surgery. Ann Thorac Surg 80: 902-909, 2005.

28. Lazar HL: Hyperglycemia during cardiac surgery. J Thorac Cardiovasc Surg 131: 11-13, 2006

29. Quinn DW, Pagano D, Bonser RS, et al: Improved myocardial protection during coronary artery surgery with glucose-insulin-potassium: a randomized controlled trial. J Thorac Cardiovasc Surg 131: 34-42, 2006. 